Talbot, J. M. \& Sneath, P. H. A. (1960). J. gen. Microbiol. 22, 303-311

\title{
A Taxonomic Study of Pasteurella septica, especially of Strains Isolated from Human Sources
}

\author{
By J. M. TALBOT* \\ Department of Bacteriology, King's College Hospital Medical School, \\ London S.E. 5 \\ AND P. H. A. SNEATH \\ National Institute for Medical Research, Mill Hill, London, N.W. 7
}

\begin{abstract}
SUMMARY: The characteristics of fifty-nine strains of Pasteurella septica, mostly derived from human lesions, were analysed by an electronic computer. The cat strains showed a high degree of similarity to each other, while the dog strains were more variable. Most human infections other than those due to bites seem to be due to strains which probably originated from cats. The analysis suggests that $P$. septica is distantly related to $P$. pestis and $P$. pseudotuberculosis but that the two latter are closely related to each other.
\end{abstract}

Most text-books of systematic bacteriology include in the genus Pasteurella the three organisms Pasteurella septica, $\boldsymbol{P}$. pestis and $\boldsymbol{P}$. pseudotuberculosis and sometimes also the causative organism of tularaemia. They usually give the haemorrhagic septicaemia bacterium as the type species of the group. Topley and Wilson's Principles (1955) pointed out that it is very doubtful whether the recognition of several distinct species is justified. There are no consistent biochemical or serological differences detectable by ordinary methods between strains of $\boldsymbol{P}$. septica isolated from different animals; to all appearances these strains are identical. A better description of the organism would be of value; it is of considerable veterinary importance and under certain circumstances may also be a human pathogen (Cawson $\&$ Talbot, 1955). The organism is a normal inhabitant of the nose and throat of dog and cat (Smith, 1955); dog and cat bites, and more rarely those of other animals (McGeachie, 1958) form one group of the human infections. The other group is made up of 'internal' infections, that is, infections not involving direct inoculation as with a bite; the majority of these are associated with the upper respiratory tract.

Systematic analysis of a large number of strains of the species by orthodox methods is not a satisfactory procedure because the similarity must necessarily be close and personal bias is likely to influence the result. The principles of classification described by Sneath $(1957 a, b)$ are based on the assumption that each feature of an organism has equal taxonomic significance. A large number of characteristics of a large number of strains can be compared easily by a mechanical device, such as an electronic computer, and the degree of

* Present address: Department of Pathology, Kingston Hospital, Kingston-on-Thames, Surrey. 
correspondence or divergence expressed mathematically; the variable human element is thus diminished. This technique has been employed here in an endeavour to re-assess the taxonomic position of Pasteurella septica, to examine strains from human sources for the existence of subgroups and to look for evidence of animal origin of human infections.

\section{METHODS}

Fifty-two strains of Pasteurella septica were obtained from human sources. About half of these were from dog or cat bites; the remainder were from 'internal' infections, the majority of these strains being isolated from sputum; the details are indicated in Fig. 1. Strains $\mathrm{C} / \mathrm{A}, \mathrm{C} / \mathrm{B}$ and $\mathrm{C} / \mathrm{C}$ are Carter's serological types $A, B$ and $C$ (Carter, 1952). Some reference strains of $P$. septica and other bacteria were also included, the origin and nature of which are shown in Table 1; the National Collection of Type Cultures (NCTC) strains are those suggested as temporary type strains by Sneath \& Cowan (1958).

Table 1. Origin and nature of reference strains

\begin{tabular}{llcc}
\multicolumn{1}{c}{ Organism } & Strain & Laboratory source & Animal source \\
Pasteurella septica & C/A & Carter (type A) & Cat \\
& C/B & Carter (type B) & Buffalo \\
& C/C & Carter (type C) & Dog \\
& Cat/7 & Dr J. E. Smith & Cat \\
& RB & Dr J. E. Smith & Rabbit \\
D/5107/51 & Dr J. E. Smith & Dog \\
& Standard & NCTC 8915 & Cattle \\
& reference & & \\
P. pestis & strain & & \\
P. pseudotuberculosis & - & NCTC 5923 & - \\
Escherichia coli & - & NCTC 8815 & - \\
E. coli & - & NCTC 8001 & - \\
Shigella dysenteriac & - & NCTC 86 & - \\
Type 1 & - & NCTC 4837 & - \\
& & &
\end{tabular}

\section{Observation of morphological and cultural characters}

Strains were grown in air or in air $+10 \%(\mathrm{v} / \mathrm{v}) \mathrm{CO}_{2}$ on $5 \%$ horse blood agar for $18 \mathrm{hr}$. at different temperatures.

Anaerobic growth was observed after overnight incubation on horse blood agar in a McIntosh \& Fildes's jar. All the strains examined grew best aerobically at $37^{\circ}$ and were Gram-negative rods showing varying degrees of pleomorphism; as these characteristics were common to all strains they were of no value for the present purposes and have been omitted from the final list of characters submitted to the computer.

Some strains were also examined by transmitted light on translucent medium (nutrient agar, $18.6 \mathrm{ml}$. + horse serum, $2.0 \mathrm{ml}$. + laked horse blood, $0.5 \mathrm{ml}$.) to observe the presence of the 'fluorescent' and 'blue' colonial appearances described by Webster \& Burn (1926).

Typical Pasteurella septica cultures have a characteristic sickly odour due 
it is believed to the production of indole; the odour is certainly absent from cultures of $\boldsymbol{P}$. haemolytica. The odour of cultures on blood agar was recorded as 'septica-like' 'coli-like' or 'other'.

Consistency and opacity of the colony in blood agar was also noted as was the presence of a capsule, determined by observation of a thin nigrosin suspension of a young culture from blood agar.

The presence or absence of growth on MacConkey's agar medium after $12 \mathrm{hr}$. at $37^{\circ}$ was noted.

The appearance of turbidity and the character of the deposit in nutrient broth was observed after incubation for $18 \mathrm{hr}$.

\section{Biochemical tests}

Fermentation reactions. Fermentation of glucose, sucrose, mannitol, galactose, sorbitol, D-xylose, maltose, adonitol, inositol, L-arabinose, dulcitol, glycerol, glycogen, salicin, lactose, raffinose, dextrin, trehalose, mannose and fructose in $1 \%(\mathrm{w} / \mathrm{v})$ solution in peptone water with Andrade's indicator was observed daily for 14 days.

Indole production. Peptone water cultures incubated overnight at $37^{\circ}$ were extracted with xylene and the xylene extract tested with Ehrlich's reagent.

Methyl-red and Voges-Proskauer reactions. Tested in the glucose-phosphate medium given in Topley and Wilson's Principles (1955, p. 450) after growth at $37^{\circ}$ for 2 days. O'Meara's modification of the Voges-Proskauer test was used as described there.

Ammonia production was observed by the addition of Nessler's reagent to a 24-48 hr. peptone-water culture.

Hydrogen sulphide production and gelatin liquefaction was observed by stab inoculation into a lead acetate + gelatin medium (lead acetate $0.25 \%, w / v$; gelatin $12.5 \%, \mathrm{w} / \mathrm{v}$; nutrient broth to $100 \mathrm{ml}$.) which was incubated at $22^{\circ}$ for 14 days.

Nitrate reduction, catalase production and reduction of methylene blue were observed as described in Topley and Wilson's Principles (1955, pp. 451-3).

Urease production. Urea agar slopes (Christensen, 1946) were incubated at $37^{\circ}$ for 14 days.

Phosphatase production was observed after $18 \mathrm{hr}$. incubation at $37^{\circ}$ on the medium of Bray \& King (1948).

Egg-yolk reaction was tested on the egg-yolk medium of Knight \& Proom (1950) which was incubated at $37^{\circ}$ for $48 \mathrm{hr}$.

Utilization of malonate and production of phenylpyruvic acid was tested in the combined medium of Shaw \& Clarke (1955) after incubation at $37^{\circ}$ for $18 \mathrm{hr}$.

Citrate utilization was observed in Koser's (1923) medium inoculated from a peptone water culture with a straight wire. A positive result was recorded when growth occurred on the second successive subculture.

Antibiotic sensitivities were determined with 'Sentest' tablets (Evans and 
Co. Ltd., Liverpool, England) on a blood agar plate flooded with an $18 \mathrm{hr}$. culture. Sulphonamide sensitivity was investigated on the medium of Jewell \& Pearmain (1954) with sulphadimidine tablets. Results were recorded as 'sensitive' or as 'resistant'.

Production of soluble haemolysin. Equal volumes of the supernatant fluid of an $18 \mathrm{hr}$. broth culture and a suspension of red cells were incubated together for $1 \mathrm{hr}$. at $37^{\circ}$. Human group $O$, horse, rabbit and sheep cells were used.

Virulence. Two white mice were inoculated intraperitoneally with $0.2 \mathrm{ml}$. of $18 \mathrm{hr}$. peptone-water culture. The strain was recorded as virulent when the animals died within $48 \mathrm{hr}$. and the organism was recovered from heart blood and spleen.

Presence of growth on potato slopes after 14 days at $37^{\circ}$ was also noted.

\section{RESULTS}

Certain observations were negative with all the strains examined and were therefore omitted from the final tabulated list, since characters which are invariably negative have no significance in a method of this kind. These characters are included in the description of the species which follows. Most of the strains examined were virulent for mice, but this character has also been omitted since virulence is not a stable character of a strain.

Table 2. Comparison of the virulence of the mucoid and smooth strains of Pasteurella septica

\begin{tabular}{|c|c|c|c|}
\hline Strain & $\begin{array}{l}\text { No. in } \\
\text { Fig. } 1\end{array}$ & Phase & $\begin{array}{c}\text { LD 50 (viable } \\
\text { organisms) }\end{array}$ \\
\hline 8045 & 59 & $\mathbf{M}$ & 10 \\
\hline Walton & 17 & $\mathbf{M}$ & 13 \\
\hline Delaney & 33 & $\mathbf{M}$ & $<82$ \\
\hline N8282 & $\mathbf{3 4}$ & $\mathbf{S}$ & 107 \\
\hline Kenney & 4 & $\mathbf{S}$ & 125 \\
\hline MacLean & 3 & $\mathbf{S}$ & 119 \\
\hline FW & 7 & $\mathbf{S}$ & $\mathbf{5 3}$ \\
\hline T55 & 11 & $\mathbf{S}$ & 63 \\
\hline
\end{tabular}

We confirmed Carter's (1957) observations that the so-called 'fluorescent' appearance described by earlier writers is in fact one of iridescence due to refraction of transmitted light round the capsular material in the colony, and that there is a straightforward $M$ (mucoid) $\rightarrow \mathbf{S}$ (smooth) $\rightarrow \mathbf{R}$ (rough) variation in this organism, as originally suggested by Rosenbusch (1937).

There is some disagreement in earlier work about the virulence of the $M$ variant; Webster \& Burn (1926) considered it to be less virulent than the $S$ strains and Carter (1957) considered its virulence to be greater. In this we agree with Carter (Table 2), but the crucial tests, comparison of $S$ and $M$ variants of the same strains, have not yet been done.

The presence of hyaluronic acid in the envelope material of the $M$ strains was confirmed by the method of Pike (1946). This hyaluronic acid is not 
immunologically active, but from analysis of the antigenic constituents of this material on agar gel-diffusion plates (Talbot; unpublished) there would seem to be some immunologically-active polysaccharide material present as well. This was observed by Carter (1958) who reported that all $M$ strains were immunologically type A.

\section{Tentative description of the species}

A description of the species Pasteurella septica, based on 59 strains, may now be given.

Morphology. The size of the organism varied according to age of the culture. At $18 \mathrm{hr}$. cultures showed organisms $c .0 \cdot 3 \times 0.5 \mu$, which were ovoid and stained bipolarly. Older cultures were more bacillary in form and were pleomorphic. Long thread forms were common in older cultures. Non-motile. Non-sporing. Not acid-fast. Gram-negative. Virulent forms sometimes showed a capsule.

Groroth on laboratory media. The organisms required blood or blood derivatives to initiate growth from small inocula. Aerobic; facultatively anaerobic. Optimum temperature near $37^{\circ}$.

After $18 \mathrm{hr}$. on blood agar, the $\mathrm{S}$ variant colonies were 0.5-1 mm. diameter, low and convex, greyish white, circular with entire edge, opaque centre and translucent periphery. The $M$ variant produced abundant mucoid capsular material, the $\mathbf{R}$ forms were much smaller, translucent and non-capsulated. Bile salt media inhibited growth.

Biochemical tests. Acid without gas produced in peptone water in $18 \mathrm{hr}$. from glucose, sucrose, mannose, and fructose; mannitol and galactose were usually fermented; xylose, sorbitol and trehalose frequently. Maltose, lactose, and glycogen (after several days) were occasionally fermented; dulcitol, arabinose and rhamnose rarely. The fermentation pattern was remarkably variable. Our strain no. 12 (from a dog-bite) was unique in that it produced a little gas from sucrose, maltose, mannose and trehalose while being in every other respect typical.

Nitrates reduced to nitrite; indole produced. The methyl red and VogesProskauer reactions were negative. Phosphatase produced. Some strains produced some urease. Ammonia was formed in peptone water; hydrogen sulphide was produced (in small amounts). Catalase produced; gelatin not liquefied nor citrate utilized. The malonate and phenyl pyruvate reactions negative. Soluble haemolysins not formed.

\section{Preparation of results for the computer}

The results of the tests given above were arranged in an $i \times m$ table (Sneath, $1957 b$ ) which recorded +, - or / (indicating 'not applicable') for each character of each strain. The table was then analysed by the Elliott 402 Digital Computer (Elliott, Bros., Elstree Way, Boreham Wood, Hertfordshire), using the programme 'Bacterial Classification Mark I'. The computer delivered the results in the form of a triangular table of percentage similarity values. This table of percentage values was inconvenient as it stood and was converted to a shaded diagram as shown in Fig. 1. 


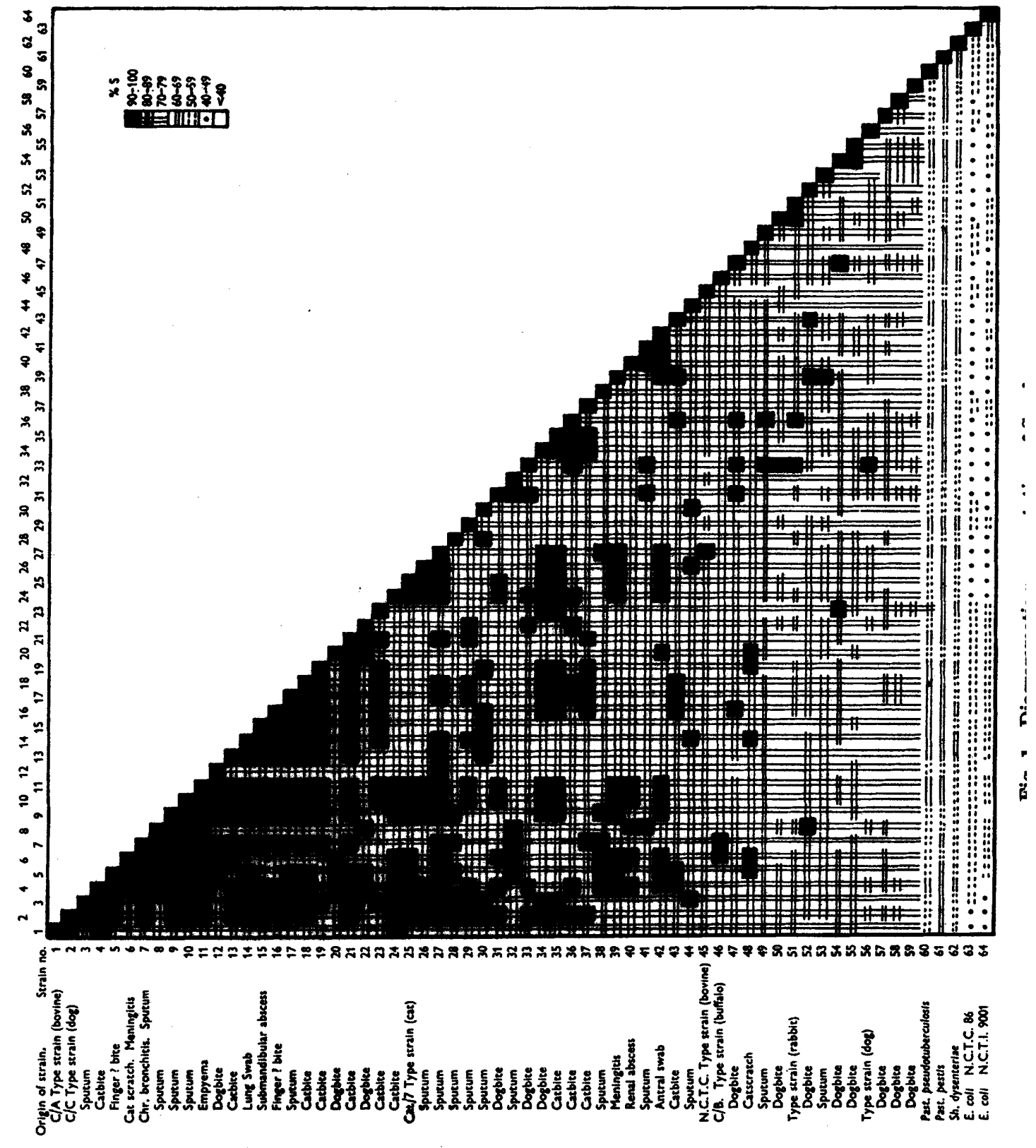




\section{DISCUSSION}

Certain observations may be made from a consideration of Fig. 1. The Pasteurella septica strains form a large group marked off from the other Gramnegative organisms examined, which included $\boldsymbol{P}$. pseudotuberculosis and $\boldsymbol{P}$. pestis. Within the $\boldsymbol{P}$. septica group there is one large subgroup which has its lower limit at strain 49. This subgroup contains all the human 'internal' strains except one, all the cat strains and half the dog strains. Within the larger subgroup there is evidence of a smaller subgroup which forms a closely related block of similar strains, composed of strains 1-19 inclusive and thereafter fading into a diffuse lower edge which cannot be delineated with any precision.

Table 3. Cumulative proportions and percentages of strains of different organisms occurring at different levels in Fig. 1

\begin{tabular}{lcrrrr} 
Origin & \multicolumn{5}{c}{ Strains in sections } \\
\cline { 3 - 6 } $\begin{array}{c}\text { Total } \\
\text { no. of }\end{array}$ & $\begin{array}{c}1-30 \\
\text { strain } \\
\text { strains }\end{array}$ & $\overbrace{1-19}$ & $\begin{array}{c}1-40 \\
\text { (Proportion and \%) }\end{array}$ & $1-49$ \\
'Internal' & 24 & $10 / 24 ;(42 \%)$ & $15 / 25 ;(63 \%)$ & $19 / 24 ;(80 \%)$ & $23 / 24 ;(97 \%)$ \\
Cat & 14 & $5 / 14 ;(36 \%)$ & $9 / 14 ;(64 \%)$ & $12 / 14 ;(85 \%)$ & $14 / 14 ;(100 \%)$ \\
Dog & 16 & $2 / 16 ;(13 \%)$ & $4 / 16 ;(25 \%)$ & $7 / 16 ;(44 \%)$ & $8 / 16 ;(50 \%)$
\end{tabular}

The proportion of strains from 'internal' lesions and from cat and dog bites which occur at different levels in the diagram is shown in Table 3. From this it is seen that the 'internal' and the cat strains are distributed in a similar manner, with the majority of strains towards the top of the diagram; this indicates that strains in these two groups are similar to each other, the inference being that cat strains (unlike those from dogs) form a characteristic and comparatively homogeneous group and that the majority of human systemic infections probably originate from cats. The role of cats as a reservoir of human infection was commented upon by Smith (1959) who examined six strains from human internal disease, one of which was our strain no. 11 (NCTC 8080). The best clinical example of this in our series is afforded by strain no. 6; this was obtained from a woman of 75 years who was scratched on the forearm by her cat 2 weeks before the onset of her illness, the scratch marks becoming inflamed and persisted for several days. She subsequently developed a purulent meningitis and died in hospital; a pure growth of Pasteurella septica was obtained from the cerebrospinal fluid (Dr A. A. Williams, private communication). While this is not conclusive, in that the organism was never obtained from the cat in question, it is highly suggestive. Carter (1959) considered that many of the strains from dogs and cats may form a separate serological type which he designated type $C$, while others fell into his types $A$ and $D$. The presence in our series of dog strains among the cat group suggests transmission by cross-infection, which might readily occur among domestic pets.

The few strains available from other animals are scattered in a random 
manner about the diagram. A group of other Gram-negative organisms with which it was thought that Pasteurella septica might have some affinity were included in this study. With the two strains of Escherichia coli and with Shigella dysenteriae there is obviously very little affinity. The two other pasteurellas show a high degree of similarity but little to the $P$. septica strains; from these they were sharply demarcated. This supports the findings of other workers (Crumpton \& Davies, 1957; Meyer, 1959) that P. pestis and P. pseudotuberculosis are much more closely allied to each other than either species is to $\boldsymbol{P}$. septica, which may eventually stand alone in the group. The present data are in reasonable agreement with those of Sneath \& Cowan (1958), though these workers noted a closer similarity between $P$. pestis and $E$. coli than has been found here. This needs further investigation.

Neither the nomenclature nor the taxonomy of the Pasteurella group is straightforward. The genus Pasteurella was created by Trevisan to include the bacillus of fowl cholera and other haemorrhagic septicaemia bacilli. The type species is undoubtedly the bacillus of fowl cholera, though as pointed out by the Editorial Board of the Judicial Commission on Bacterial Nomenclature the correct name is in doubt. The Judicial Commission (1954) conserved the generic name $\boldsymbol{P a s t e u r e l l a}$ and apparently accepted the name $\boldsymbol{P}$. cholerae-gallinarum for the type species. This cumbersome and almost forgotten name would be the correct name for $\boldsymbol{P}$. septica if (as seems almost certain) the other haemorrhagic septicaemia bacilli belong to the same species as the fowl cholera bacillus. For this situation Breed, Lessel, Clise \& Merchant in Bergey's Manual (1957) recommended that the Judicial Commission should conserve a better known specific epithet such as 'septica' (Topley and Wilson's Principles, 1955) or 'multocida' (used in Bergey's Manual).

Whether Pasteurella pestis and $\boldsymbol{P}$. pseudotuberculosis should be moved to another genus is debatable; if so, the correct generic name would apparently be $Y$ ersinia van Loghem 1946 (this appears to be validly published, and the type species should be $Y$. pestis, though the actual binomials $Y$. pestis and $Y$. pseudotuberculosis were not given). Yet there is evidence of close relationship with certain enterobacteria, and it seems to us unwise to use a new generic name in a group which, as emphasized by Cowan (1956), has far more generic names already than is really justified.

Our thanks are due to pathologists who have supplied us with strains and also to Dr A. C. Cunliffe for helpful discussion and comment.

\section{REFERENCES}

Bergey's Manual of Determinative Bacteriology, (1957). 7th ed. Ed. R. S. Breed, E. D. G. Murray \& N. R. Smith, pp. 895, 402. Baltimore: Williams and Wilkins. Bray, J. \& KING, R. J. (1943). The phosphatase reaction as an aid to the identification of microorganisms using phenolphthalein phosphate as a substrate. J. Path. Bact. 55, 315.

Carmer, G. R. (1952). The type specific capsular antigen of Pasteurella multocida. Canad. J. med. Sci. 30, 48. 
Carter, G. R. (1957). Studies on Pasteurella multocida. II. Identification of antigenic characteristics and colonial variants. Amer. J. vet. Res. 18, 210.

Carter, G. R. (1958). Some characteristics of Type A strain of Pasteurella multocida. Brit. vet. J. 114, 356.

Carter, G. R. (1959). Studies on Pasteurella multocida. IV. Serological types from species other than cattle and swine. Amer. J. vet. Res. 20, 173.

Cawson, R. A. \& Talbot, J. M. (1955). The occurrence of Pasteurella septica (Syn. multocida) in bronchiectasis. J. clin. Path. 8, 49.

Christransen, W. B. (1946). Urea decomposition as a means of differentiating Proteus and paracolon organisms from each other and from Salmonella and Shigella types. J. Bact. 52, 461.

Cowan, S. T. (1956). Taxonomic rank of Enterobacteriaceae 'Groups'. J. gen. Microbiol. 15, 345.

Crumpton, M. J. \& Davies, D. A. L. (1957). A protein antigen associated with smooth colony forms of some species of Pasteurella. Nature, Lond. 180, 863.

Edrtoriar Board (1958). Status of generic names proposed by Trevisan. Int. Bull. bact. Nomencl. 3, 87 .

Jeweil, P. \& Pearmañ, G. E. G. (1954). A routine method for testing the sulphonamide sensitivity of organisms causing urinary infections. J. clin. Path. 7, 308.

Judicial Commission (1954). Opinion 18. Conservation and rejection of names of genera of bacteria proposed by Trevisan 1842-1890. Int. Bull. bact. Nomencl. $4,151$.

Kngart, B. C. J. G. \& Proom, H. (1950). A comparative study of the nutrition and physiology of mesophilic species in the genus Bacillus. J. gen. Microbiol. 4, 508.

KosEr, S. A. (1923). Utilization of the salts of organic acids by the colon-aerogenes group. J. Bact. 8, 498.

McGrachie, J. (1958). Isolation of Pasteurella septica from a lion-bite wound and lion's mouth. J. Path. Bact. 75, 467.

MeYen, K. (1959). In Bacterial and Mycotic Infection of Man, 3rd ed. Ed. R. Dubos, p. 400. Philadephia: J. B. Lippincott \& Co.

Pukx, R. M. (1946). A study of Group A streptococei from healthy carriers with particular attention to mucoid polysaccharide production. J. infect. Dis. 79, 148.

Rosensusch, G. I. (1987). Biologic and serologic relationships of the haemorrhagic septicaemia pasteurellae. M.S. Thesis. Iowa State College, U.S.A.

Shaw, C. \& Clarke, P. H. (1955). Biochemical classification of Proteus and Providence cultures. J. gen. Microbiol. 13, 155.

Smrth, J. E. (1955). Studies on Pasteurella septica. I. The occurrence in the nose and tonsils of dogs. J. comp. Path. 65, 239.

Smrth, J. E. (1959). Studies on Pasteurella septica. III. Strains from human beings. J. comp. Path. 69, 281.

S NEATH, P. H. A. $(1957 a)$. Some thoughts on bacterial classification J. gen. Microbiol. 17, 184.

SNEATH, P. H. A. (1957b). The application of computers to taxonomy. J. gen. Microbiol. 17, 201.

Sneath, P. H. A. \& Cowan, S. T. (1958). An electrotaxonomic survey of bacteria. J. gen. Microbiol. 19, 551.

Topley and Wilson's Principles of Bacteriology and Immunity (1955). 4th ed. Ed. G. S. Wilson \& A. A. Miles, London: Edward Arnold.

Webster, L. T. \& BURN, C. G. (1926). Biology of Bacterium lepisepticum. III. Physical, cultural and growth characteristics of diffuse and mucoid types and their variants. J. exp. Med. 44, 348.

vaN LogheM, J. J. (1946). La classification du bacille pesteux. (Yersinia gen.nov.) Ann. Inst. Pasteur, 72, 975.

(Received 8 September 1959) 